\title{
MEASUREMENTS OF STUDENTS' WELLBEING - CASE STUDY IN A LATVIAN PRIVATE SCHOOL
}

\author{
Svetlana Usca ${ }^{1}$, Antra Klavinska ${ }^{2}$, Inta Rimsane ${ }^{3}$ \\ ${ }_{1,2,3}$ Rezekne Academy of Technologies, Latvia
}

\begin{abstract}
Currently, there is too much emphasis on academic attainment and rankings, and not enough focus on the student wellbeing in basic school. However, the education system (especially in the context of the Covid-19 pandemic) has a significant opportunity to influence the health and habit formation of students who spend the greatest part of the day at school. There have been relatively few studies on student wellbeing in Latvia. The most significant research has been carried out in collaboration with the researchers from the Baltic countries (Estonia, Lithuania). The novelty of this research is related to the development of the theoretically and methodologically based indicators for measuring student wellbeing in an educational institution. The developed indicators will allow the teachers to clarify the situation, draw conclusions and improve the organizational culture.

The goal of the research is to find out which indicators reflect the student wellbeing and how to measure them. Based on the study and theoretical findings about the wellbeing indicators there was developed the questionnaire, which consists of self-assessment check list filled by students and evaluation check list filled by parents and teachers. The indicators were united into four wellbeing dimensions: mental wellbeing, cognitive wellbeing, social wellbeing, and physical wellbeing.

The following participants filled in the check list and participated in the approbation of the questionnaire: 18 students ages 9-12, 18 parents and 18 teachers.

It was suggested to assess the statements related to social, cognitive, physical and mental wellbeing following the Likert scale. The data obtained in the survey was coded and processed in the program SPSS 25.0, using the Frequency test, T-test, ANOVA test. Results indicated that students' sense of wellbeing is changeable. It is influenced by students' age and gender, and their personal value system. Therefore, measurement of student wellbeing should be done on regular bases. This will allow teachers to create an appropriate environment for the student, as well as to identify problems in a timely manner and, if necessary, start pedagogical correction work. Keywords: cognitive wellbeing, psychological wellbeing, physical wellbeing, social wellbeing, student wellbeing, case study.
\end{abstract}

To cite this article:

Usca, S., Kḷavinska, A., \& Rimsane, I. (2020). Measurements of Students’ Wellbeing - Case Study in a Latvian Private School. Education. Innovation. Diversity, 1(1), 48-56.

DOI: http://dx.doi.org/10.17770/eid2020.1.5333

\section{Introduction}

The coronavirus pandemic has created disruption of education systems, which are facing the serious challenges for the policy-makers, school leaders, teachers, pupils and parents: from the traditional classroom situation and face to face contact with the teacher to distance learning via internet and active participation in e-learning environment. Everyone has to learn how to cope with the stress, support each other, use new technologies and choose between the most and the less important issues. Additionally, the education system of Latvia has started the transition to the new curriculum and competency-based learning. Restructuring of the learning process and uncertainty associated with it affect the wellbeing of all the involved persons: students, teachers and parents.

Lately the national and international conferences of Latvia bring up the question if the student wellbeing is more important now, during the pandemic, than in pre-COVID-19 because the positive atmosphere and support in the study process lead to better performance on tests.

„Wellbeing is diverse and fluid respecting individual, family and community beliefs, values, experiences, culture, opportunities and contexts across time and change. It encompasses 
intertwined individual, connective and environmental elements which continually interact across the lifespan. Wellbeing is something we all aim for, underpinned by notions, yet it is unique for each of us and provides us with a sense of who we are which needs to be respected. Our role with wellbeing education is to provide the opportunity, access, choices, resources and capacities for individuals and communities to aspire to their unique sense of wellbeing, whilst contributing to a sense of community wellbeing" (Price \& McCallum, 2016, 17).

The idea to explore the student wellbeing arose while working in the project "Strengthening the academic staff of Rezekne Academy of Technologies in the study field "Education, pedagogy and sports", 8.2.2.0/18/I/002. The authors of the article had an internship in one of few private schools of Latvia which follows the key words "freedom", "choice" and "responsibility" in the study process. The school has small class sizes from the first to sixth grade and small number of teaching staff. All of them have the responsibility to ensure the safe, dignified, positive and supportive atmosphere which focuses on the cooperation between students, parents and teachers. One of the most important school objectives: to ensure the qualitative development and education process that results in the school graduates who are able to love, respect, support, make choices and decisions, set and achieve goals, think and solve life tasks, take responsibility, cooperate, create and improve their own and society's lives. The school enhances not only cognitive, but also psychological, social and physical wellbeing of the students. In the authors' opinion, many schools of Latvia pay too much emphasis on academic attainment and rankings but ignore the student wellbeing.

The goal of the research is to find out which indicators reflect the objective measurements of the student wellbeing: external conditions (school strategy, organizational culture) or correlation with the students' own value system.

The research objectives: 1) to find out the meaning of the concept of "wellbeing" in the educational science; 2) to determine the methodological approaches for measuring student wellbeing, 3) to develop a questionnaire based on scientific data for the assessment of student wellbeing, 4) to approbate and improve the questionnaire (self-assessment check list) of student wellbeing by conducting a pilot study at school.

In 2015, the extensive theoretically grounded research on student wellbeing has been conducted by PISA (the Program for International Student Assessment) which examined 15year-old students' wellbeing in four main areas of their lives: performance in school, relationships with peers and teachers, home life, and how they spend their time outside the school. On average across OECD countries, students reported a level of 7.3 on a life-satisfaction scale ranging from 0 to 10 . However, about $12 \%$ of students, on average across OECD countries - and more than $20 \%$ of students in some countries - reported that they are not satisfied with their life (they rated their satisfaction with life 4 or less on the scale) (OECD, 2017).

There have been relatively few studies on student wellbeing in Latvia. The most significant research has been carried out in collaboration with the researchers from the Baltic countries (Lithuania and Estonia) in different international projects: "Wellbeing and Welfare of Children in the Baltic States: study report and recommendations" (Nordic Council of Minister's Office in Latvia, Žiburio Fondas, Latvian Child Welfare Network, Lapse Huvikaitse Koda, 2017) and "Wellbeing of Young People in the Baltic States: research report" (Agency for International Programs for Youth, 2019). Both studies have developed the system of child and youth wellbeing indicators, which allow a regular comparison of wellbeing in the Baltic States and internationally.

The novelty of this research is related to the development of the theoretically and methodologically based indicators for measuring pupils' wellbeing in an educational institution. The developed indicators will allow the teachers clarify the situation, draw conclusions and improve the organizational culture. 


\section{Understanding of the concept of wellbeing in the context of education}

Ryff (1995) associates personality wellbeing with such aspects of growth as development and self-realization, emphasizing the following factors: self-acceptance (positive attitude towards oneself, positive mood); positive relationships (trusting relationships with others, developed empathy); autonomy (ability to resist social pressure, self-regulation of behavior, ability to evaluate oneself according to the internal value system); personal growth (ability to move towards one's own improvement, development, openness to the new, behavior expresses knowledge and efficiency); existence of a goal, competence (ability to effectively use the surrounding opportunities, make choices according to values and needs). Recent research views personality wellbeing as a complex concept, as the sum of cognitive, social, psychological, physical, and material wellbeing (Borgonovi \& Pál, 2016; Diaz, Blanco, \& Mar, 2011).

Cognitive wellbeing refers to the skills and foundations students have to participate effectively in society, as lifelong learners, effective workers and engaged citizens. It comprises students' proficiency in academic subjects, their ability to collaborate with others to solve problems and their sense of mastery in-school subjects. It incorporates actions and behaviors that may promote the acquisition of knowledge, skills or information that may aid them when they are faced with new, complex ideas and problems (Pollard \& Lee, 2003).

The psychological dimension of student wellbeing includes students' evaluations and views about life, their engagement with school, and the goals and ambitions they have for their future (Borgonovi, \& Pál, 2016), as well as efficiency and competence (Becker, 1991).

The physical dimension of student wellbeing refers to students' health status, engagement in physical exercise and the adoption of healthy eating habits (Statham \& Chase, 2010). Physical wellbeing is characterized by the following indicators: satisfaction with one's body; balance of rest and leisure time; vitality and joy of life; pleasant fatigue; feeling of joy; ability to concentrate and react adequately; a feeling of a clean and wellgroomed body (Frank, 2004). Indicators of physical balance and goodness include several aspects: a sense of peace and physical liberation; vitality and joy of life; ability to relax the body in cases of increasing fatigue; feelings of joy and "taste of life"; concentration and response skills; a sense of hygiene and enjoyment of one's body (Wydra, 2014).

The social dimension of student wellbeing refers to the quality of their social lives (Rath, Harter, \& Harter, 2010) including their relationship with their family, their peers and their teachers, and how they perceive their social life in school (Pollard \& Lee, 2003), as well as desire to be loved and needed (Becker, 1991).

Material resources make it possible for families to care for their children's needs and for schools to support students' learning and healthy development. Households who live in poverty find it difficult to ensure that their children have access to the educational and cultural resources they need to thrive in school and to realize their potential. Children who live in poverty - with poor housing conditions and poor diets - are more likely to have health problems (Aber et al., 1997).

So the model of wellbeing is multidimensional. There are four categories of variables related to school: 1) school environment (e.g. school organization), 2) social relations (e.g. teacher-student relationship, peer relationship), 3) self-actualization (e.g. value of students' work); 4) personal health, satisfaction with the state of the body (Tobia et al, 2018; Wydra, 2014). 


\section{Methodology}

One of the most important methodological materials for measuring wellbeing is „A framework for the analysis of student wellbeing in the PISA 2015 study" which provides a comprehensive overview and details the policy relevance of the following five dimensions of wellbeing: cognitive, psychological, social, physical and material wellbeing. The paper outlines the underlying indicators of each dimension and their theoretical and analytical value for education policy. This paper concludes by identifying data gaps within the indicators and exploring how future cycles of PISA could bridge these gaps in order to provide a more comprehensive portrait of students' wellbeing” (Borgonovi \& Pál, 2016, 4).

Based on the study and theoretical findings about the wellbeing indicators there was developed the questionnaire (Becker, 1991; Diaz, Blanco, \& Mar, 2011; Frank, 2004; Ryff \& Keyes, 1995; Tobia et al, 2018; Wydra, 2014, etc.) which consists of self-assessment check list filled by students and evaluation check list filled by their parents and teachers. The indicators were united into four wellbeing dimensions: mental, cognitive, social and physical wellbeing (see Figure 1).

The following participants filled in the check list and participated in the approbation of the questionnaire: 18 students ages 9-12, 18 parents and 18 teachers. All groups of respondents were asked to rate the same items on a five point Likert scale where 1 - definitely disagree, 2 agree more than disagree, 3 - don't know, 4 - agree more than disagree, 5 - strongly agree.

In the research the about students' wellbeing in the private school, the triangulation was used to capture different dimensions of the same data and avoid subjective approach. The data obtained in the survey was coded and processed in the program SPSS 25.0, using the Frequency test, T-test, ANOVA test.

\section{Results}

The results analysis included the assessment of the factors and individual statements. The obtained results reflect the assessment statements of all the respondents and each group (Figure 1).

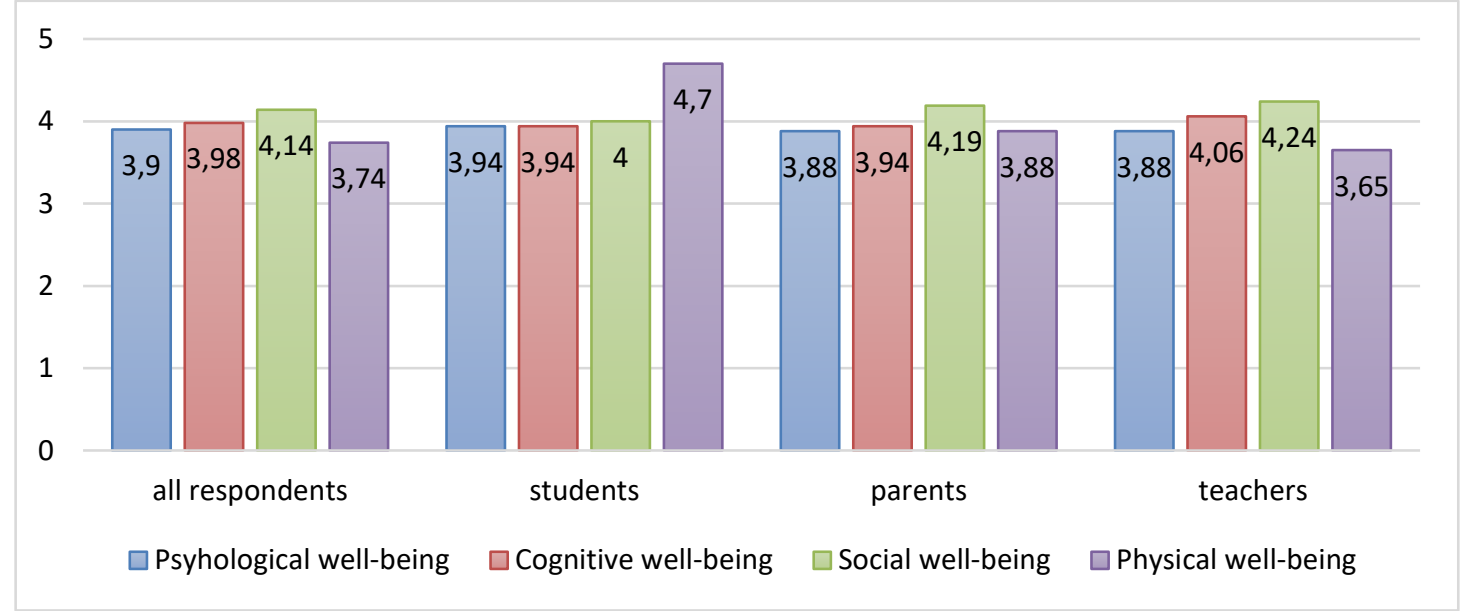

Figure 1 Average values in the diverse groups of respondents

The factor analyses of all the respondent groups reflect the highest average value for the factor Social wellbeing (Mean 4.14), followed by Cognitive wellbeing (Mean 3.98) and Psychological wellbeing (Mean 3.90). The lowest average value is for the factor Physical wellbeing (Mean 3.74). The results show statistically significant differences depending on the 
respondents' groups (students, teachers, parents) in the assessments of the Psychological wellbeing $(\mathrm{p}=.001)$ and Social wellbeing $(\mathrm{p}=.027)$. The factor Physical wellbeing has the highest evaluation in the students' answers. There are studies (Costigan, Lubans, Lonsdale, Sanders, \& del Pozo Cruz, 2019) that emphasize that the time spent in physical activity improves the person's overall wellbeing. The data was collected at school where the students spend a lot of time outdoors and physical activity is a regular part of their lives. This explains the high average value of the factor Physical wellbeing.

In the teachers' responses, the particular emphasis is given to the factors Social wellbeing and Cognitive wellbeing, which can be closely linked to the professional activity and its impact on the assessment criteria. Factor Social wellbeing was rated higher in parents' answers.

Statement analyses reflects the statistically significant differences between the respondent groups (Table 1).

\section{Table 1 Average values of the statements and statistically significant differences between the respondent groups}

\begin{tabular}{|l|c|c|c|c|}
\hline Statement & Students & Teachers & Parents & p \\
\hline Student likes school premises & 4,29 & 4,82 & 4,81 & $\mathbf{, 0 0 5}$ \\
\hline Other people think that the student is a responsive, good person & 3,41 & 4,41 & 4,25 & $\mathbf{0 0 5}$ \\
\hline Student is not afraid to express her/his opinion & 3,41 & 1,53 & 1,69 & $\mathbf{, 0 0 0}$ \\
\hline $\begin{array}{l}\text { People seldom manage to persuade the student to do what he does } \\
\text { not want }\end{array}$ & 3,35 & 2,12 & 2,81 & $\mathbf{, 0 1 1}$ \\
\hline It is difficult for a student to express her/his opinion at school & 2,76 & 1,53 & 1,75 & $\mathbf{, 0 0 4}$ \\
\hline Student is proud of himself & 3,88 & 4,47 & 3,75 & $\mathbf{0 0 3 1}$ \\
\hline Student likes to find out something new every day & 3,88 & 4,35 & 4,75 & $\mathbf{, 0 2 5}$ \\
\hline Student likes to learn something new every day & 3,82 & 4,35 & 4,56 & $\mathbf{0 4 5}$ \\
\hline Student enjoys conversations with classmates and schoolmates & 4,06 & 4,82 & 4,56 & $\mathbf{0 0 4}$ \\
\hline Student is happy to help others & 4,12 & 4,59 & 4,81 & $\mathbf{0 0 0}$ \\
\hline Student often feels very tired & 3,00 & 2,00 & 2,13 & $\mathbf{, 0 1 8}$ \\
\hline
\end{tabular}

On the other hand, the analysis of students' answers provides the statistically significant differences (depending on students' ages) in measuring the Mental wellbeing $(p=.047)$ and Physical wellbeing $(\mathrm{p}=.005)$. There were statistically significant differences between male and female students in measuring the Physical wellbeing $(p=.043)$.

The results show that measuring the wellbeing factors and indicators can be modified by students' ages, gender or respondents' sense of belonging to a particular group (student, teacher or parent). This allows us to assume that the student wellbeing has to be measured at school on a regular basis (at least once a year). This will allow teachers to create the supportive environment for the students, as well as to identify problems and, if necessary, start pedagogical correction in a timely manner.

\section{Discussion and conclusions}

The developed questionnaire was based on triangulation so diverse viewpoints appear in the research. The questionnaire, on the one hand, reflects a broad definition of the student wellbeing, on the other hand, faces limitations of the detailed analyses. Sometimes subjective wellbeing depends on value priorities (Sortheix \& Lönnqvist, 2014, 2015).

Needs and wellbeing are related to values so the personal value system can affect the measurement of wellbeing components (Lyubomirsky, Sheldon, \& Schkade, 2005; Bobowik, 
Basabe, Paez, Jimenez-Aristizabal, \& Bilbao, 2011). Values are related to motivation that influences attitudes, behaviors, and measurements (Fischer \& Boer 2016). Measurement of the wellbeing factors and related indicators highlight also the students' values, which are related to the motivation to take action and to the needs necessary for improving wellbeing.

The gained data led to the necessity to design the new questionnaire which included the most important measuring indicators for the students. The questionnaire could provide a broader picture of the students' values and needs to increase the personal wellbeing. The designing of the new questionnaire is also based on the fact that the schools need the ongoing work for measuring the student wellbeing. The new questionnaire was improved by offering the students to measure the personal significance of each statement (Importance) and the relevance of the school community to the students' needs (Reality). The improved questionnaire is shown in Table 2.

Table 2 Students' questionnaire

\begin{tabular}{|c|c|c|c|c|c|c|c|c|c|c|}
\hline \multicolumn{5}{|c|}{$\begin{array}{l}\text { Importance } \\
\text { (how much it is } \\
\text { important for you) }\end{array}$} & \multirow[b]{2}{*}{ Statement } & \multicolumn{5}{|c|}{$\begin{array}{l}\text { Reality (to what extent } \\
\text { it is provided at school) }\end{array}$} \\
\hline 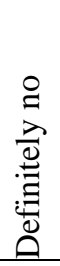 & $\begin{array}{l}\stackrel{0}{0} \\
\lambda \\
0 \\
0 \\
0 \\
0 \\
0\end{array}$ & 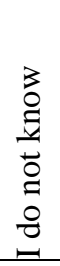 & 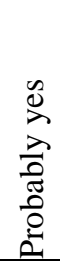 & 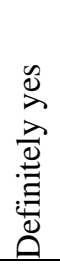 & & 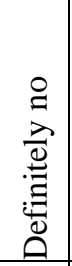 & 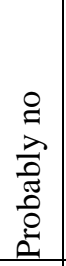 & $\begin{array}{l}3 \\
0 \\
0 \\
\vdots \\
0 \\
0 \\
0 \\
0 \\
- \\
-\end{array}$ & $\begin{array}{l}0 \\
\Delta \\
\lambda \\
\frac{0}{0} \\
\tilde{\pi} \\
0 \\
0 \\
0\end{array}$ & 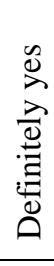 \\
\hline & & & & & I like school premises & & & & & \\
\hline & & & & & I have friends at school & & & & & \\
\hline & & & & & I feel lonely at school & & & & & \\
\hline & & & & & People around me consider me a responsive, good person & & & & & \\
\hline & & & & & I'm not afraid to express my thoughts at school & & & & & \\
\hline & & & & & $\begin{array}{l}\text { People rarely manage to persuade me to do what I don't } \\
\text { want to do }\end{array}$ & & & & & \\
\hline & & & & & $\begin{array}{l}\text { It is more important at school to adapt to others than to } \\
\text { be alone }\end{array}$ & & & & & \\
\hline & & & & & I feel safe at school: I'm not called, beaten, not robbed & & & & & \\
\hline & & & & & Teachers are demanding and honest with me & & & & & \\
\hline & & & & & It's hard for me to express my thoughts at school & & & & & \\
\hline & & & & & $\begin{array}{l}\text { If I have problems at school I know to whom to turn to } \\
\text { solve them }\end{array}$ & & & & & \\
\hline & & & & & I am responsible for what I do & & & & & \\
\hline & & & & & Studying at school depresses me & & & & & \\
\hline & & & & & I am proud of myself & & & & & \\
\hline & & & & & I'm sure I can do almost anything & & & & & \\
\hline & & & & & Overall, I like myself at school & & & & & \\
\hline & & & & & I am not satisfied with my progress / achievements & & & & & \\
\hline & & & & & I have more disadvantages than other students & & & & & \\
\hline & & & & & At school I am afraid of punishment & & & & & \\
\hline & & & & & $\begin{array}{l}\text { We participate in various competitions and events with } \\
\text { class / schoolmates }\end{array}$ & & & & & \\
\hline & & & & & I can cope with school tasks on my own & & & & & \\
\hline & & & & & I can plan my time to manage everything & & & & & \\
\hline & & & & & I find it difficult to do school tasks & & & & & \\
\hline & & & & & I don't like to plan a day & & & & & \\
\hline
\end{tabular}




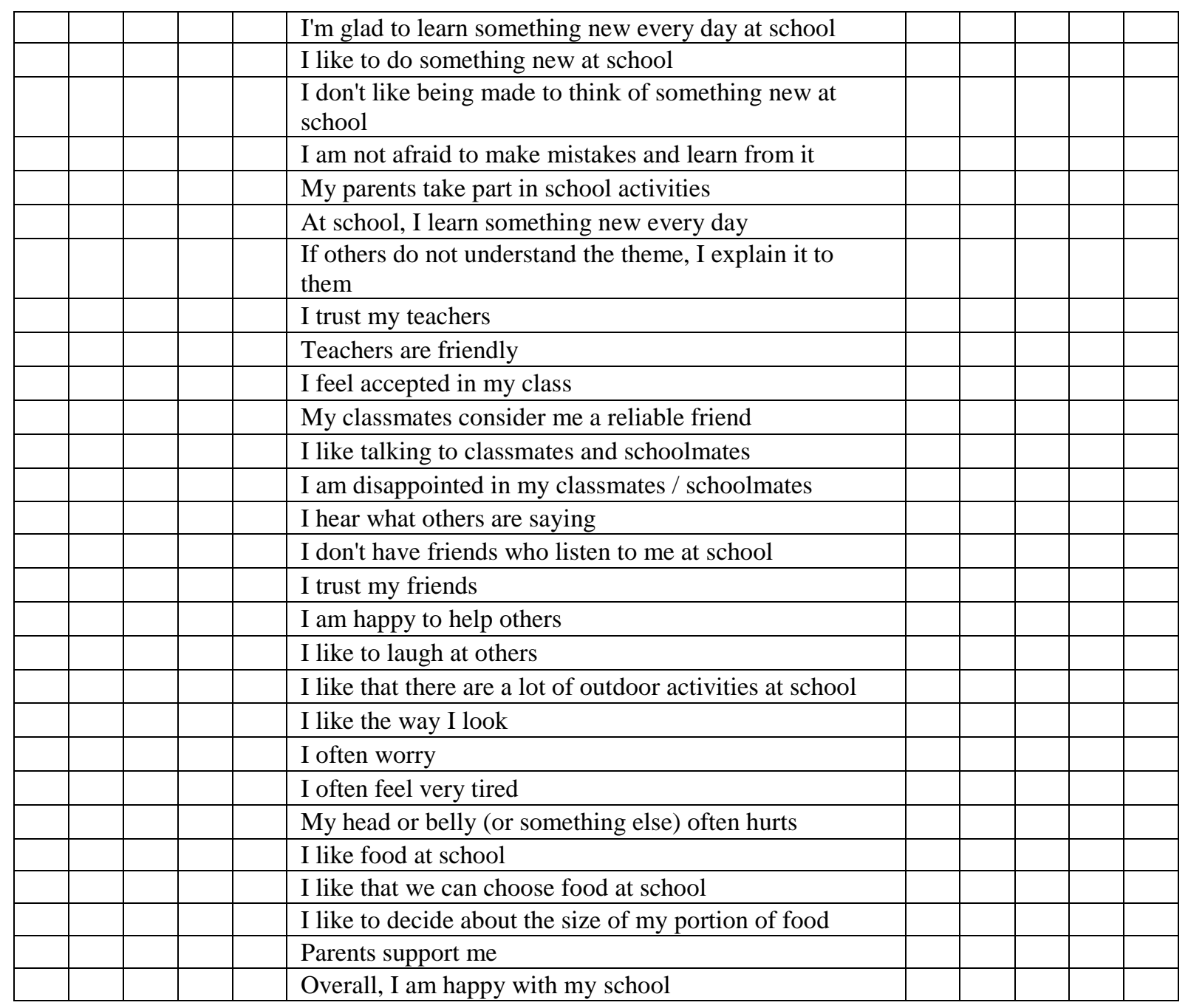

We assume that the proposed students' self-assessment questionnaire would allow:

1) to identify the degree to which a student is feeling well at school, because students and adults (teachers, parents) may focus on different issues while answering the questions. The comparison between Importance and Reality would allow students to more accurately evaluate their needs and the school environment.

2) to analyze the students' value principles and, if necessary, implement the correcting pedagogy in the classroom.

The data from PISA research about student wellbeing show that „many of the differences, both between and within countries, in student wellbeing are related to students' perceptions about the disciplinary climate in the classroom or about the support their teachers give them. In particular, schools can help eradicate bullying in partnerships with parents, community organisations and health or social services. The data also show that parental involvement and adolescents' perceptions about the support their parents give them are associated with students' feelings about schoolwork, their performance in PISA and their wellbeing, in general. The results suggest that forging stronger relationships between schools and parents to give adolescents the support they need - academically and psychologically - could go a long way towards improving the wellbeing of all students" (OECD 2017, 20).

It is possible to measure the student wellbeing and make improvements only using the qualitative and methodologically accurate case studies. 
The questionnaire needs to be approbated in several educational institutions. As a result, there will be created the measurement tool to collect the evidence of student wellbeing at basic school.

\section{References}

Agency for International Programs for Youth, Republic of Latvia (2019). Wellbeing of Young People in Baltic States: Research Report. Riga-Tallin-Vilnius. http://www.bernulabklajiba.lv/wp-content/uploads/2019/04/Well-being-of-YoungPeople-in-the-Baltic-States_2018_ENG_Final.pdf

Aber, J., L. et al. (1997). The effects of poverty on child health and development. Annual Review of Public Health, Vol. 18/1, 463-483. Doi: http://dx.doi.org/10.1146/annurev.publhealth.18.1.463.

Becker, P. (1991). Terminologie und Struktur des Wohlbefindens. In: A.Abele, P.Becker Hrsg.: Wohlbefinden Theorie-Empirie-Diagnostik Juventa (pp.13-16). Weiheim und München.

Bobowik, M., Basabe, N., Paez, D., Jimenez-Aristizabal, A., \& Bilbao, M. A. (2011). Personal values and wellbeing among Europeans, Spanish natives and immigrants to Spain: Does the culture matter? Journal of Happiness Studies, 12, 401-419. Doi:10.1007/s10902-0109202-1

Borgonovi, F. \& Pál, J. (2016). A framework for the analysis of student wellbeing in the PISA 2015 study. OECD Education Working Papers, No. 140, OECD Publishing, Paris. Doi: http://dx.doi.org/10.1787/5jlpszwghvvb-en

Costigan, S. A., Lubans, D. R., Lonsdale, C., Sanders, T., \& del Pozo Cruz, B. (2019). Associations between physical activity intensity and wellbeing in adolescents. Preventive medicine, 125, 55-61. Doi: https://doi.org/10.1016/j.ypmed.2019.05.009

Diaz, D., Blanco, A., \& Mar, D. M. (2011). The Structure of wellbeing: The empirical encounter of three traditions. Revista De Psicologia Social, 26(3), 357-372.

Doi: https://doi.org/10.1174/021347411797361266

Fischer, R. \& Boer, D. (2016). Values: the dynamic nexus between biology, ecology and culture. Current Opinnion Psychology, 8, 155-160. Doi: https://doi.org/10.1016/j.copsyc.2015.12.009

Frank, E. (2004). Physician health and patient care. Journal of the American Medical association, 291(5), 637. doi:10.1001/jama.291.5.637

Lyubomirsky, S., Sheldon, K. M., \& Schkade, D. A. (2005). Pursuing happiness: The architecture of sustainable change. Review of General Psychology, 9, 111-131. Doi:10.1037/1089- 2680.9.2.111

Nordic Council of Minister's Office in Latvia, Žiburio Fondas, Latvian Child Welfare Network, Lapse Huvikaitse Koda (2017). Wellbeing and Welfare of Children in Baltic Countries: Study Report and Recomendations. http://www.bernulabklajiba.lv/wpcontent/uploads/2017/06/Children-Well-Being-in-Baltic-

Countries_Report_2017_final.pdf

OECD (2017). PISA 2015 Results (Volume III): Students' WellBeing. PISA, OECD Publishing, Paris. http://dx.doi.org/10.1787/9789264273856-ne

Pollard, E. L., \& Lee, P. D. (2003).Child wellbeing: A systematic review of the literature.

Social Indicators Research, Vol. 61/1, 59-78, http://dx.doi.org/10.1023/A:1021284215801 .

Price, D., \& McCallum, F. (2016). Wellbeing in education. In: McCallum, F. \& Price, D. (eds). Nurturing wellbeing development in education: From little things, big things grow. London, New York: Routlege, 1-21. 
Rath, T., Harter, J. \& Harter, J., K. (2010). Wellbeing: The Five Essential Elements. New York: Gallup Press.

Ryff, C. D., \& Keyes, C. L. M. (1995). The structure of psychological wellbeing revisited. Journal of personality and social psychology, 69(4), 719.

Sortheix, F.M. \& Lönnqvist, J.E. (2014). Personal value priorities and life satisfaction in Europe the moderating role of socioeconomic development. Journal of Cross-Cultural Psychology, 45(2), 282-299. Doi: https://doi.org/10.1177\%2F0022022113504621

Sortheix, F.M. \& Lönnqvist, J.E. (2015). Person-group value congruence and subjective wellbeing in students from Argentina, Bulgaria and Finland: the role of interpersonal relationships. Journal of Community \& Applied Social Psycholology, 25(1), 34-48. Doi: https://doi.org/10.1002/casp.2193

Statham, J., \& Chase, E. (2010). Childhood Wellbeing: A Brief Overview. Childhood Wellbeing Research Centre, Loughborough, UK.

Tobia, V., Greco, A., Steca, P., \& Marzocchi, G. M. (2019). Children's wellbeing at school: A multi-dimensional and multi-informant approach. Journal of Happiness Studies, 20(3), 841-861. Doi: 10.1007/s10902-018-9974-2

Wydra, G. (2014). Der Fragebogen zum allgemeinen habituellen Wohlbefinden. Retrieved from http://www.sportpaedagogik-sb.de/pdf/FAHW-Manual.pdf 